Virginia Commonwealth University vCU Scholars Compass

\title{
One-step femtosecond laser ablation synthesis of sub-3 nm gold nanoparticles stabilized by silica
}

Mallory G. John

VCU

Katharine M. Tibbetts

VCU,kmtibbetts@vcu.edu

Follow this and additional works at: https://scholarscompass.vcu.edu/chem_pubs

Part of the Chemistry Commons

\section{Downloaded from}

https://scholarscompass.vcu.edu/chem_pubs/90

This Article is brought to you for free and open access by the Dept. of Chemistry at VCU Scholars Compass. It has been accepted for inclusion in Chemistry Publications by an authorized administrator of VCU Scholars Compass. For more information, please contact libcompass@vcu.edu. 


\title{
One-step femtosecond laser ablation synthesis of sub-3 nm gold nanoparticles stabilized by silica
}

\author{
Mallory G. John and Katharine Moore Tibbetts \\ Department of Chemistry, Virginia Commonwealth University, Richmond, VA 23284, USA
}

\begin{abstract}
We report the synthesis of silica-gold nanoparticles (silica-Au NPs) using a one-step femtosecond-reactive laser ablation in liquid (fs-RLAL) technique by focusing femtosecond laser pulses onto a silicon wafer immersed in an aqueous $\mathrm{KAuCl}_{4}$ solution. Characterization of the silica-Au NPs revealed two populations of Au NPs: (i) larger, isolated Au NPs with diameter 7.0 $2.0 \mathrm{~nm}$, and (ii) smaller Au NPs $(1.9 \pm 0.7 \mathrm{~nm})$ stabilized by an amorphous silica matrix, along with new species of silicon observed from XPS analysis. The silica-Au NPs were catalytically active towards the model reaction of para-nitrophenol reduction by $\mathrm{NaBH}_{4}$. The formation of the two populations of silica-Au NPs is ascribed to reaction dynamics occurring on two distinct timescales. First, the dense electron plasma formed within tens of femtoseconds of the laser pulse initiates reduction of the $\left[\mathrm{AuCl}_{4}\right]^{-}$complex, leading to the formation of larger isolated $\mathrm{Au}$ NPs. Second, silicon species ejected from the wafer surface hundreds of picoseconds or later after the initial laser pulse reduce the remaining $\left[\mathrm{AuCl}_{4}\right]^{-}$and encapsulate the growing clusters, forming ultrasmall Au NPs stabilized by the silica matrix. The morphologies of the silica-Au NPs generated from fs-RLAL are distinct from those reported in recent RLAL experiments with nanosecond lasers, reflecting distinct mechanisms occurring on the different pulse duration timescales.
\end{abstract}

Keywords: reactive laser ablation in liquid, femtosecond laser, silica-gold

${ }^{1}$ kmtibbetts@vcu.edu 
nanomaterial, nanocatalyst

\section{Introduction}

Pulsed laser ablation in liquid (PLAL) has emerged as a rapidly growing field since the initial report of metal nanoparticle (NP) synthesis using this technique in 1993 [1], with many subsequent demonstrations of the versatility and simplicity of the method [2 4]. Growing interest in this field is driven by the ability to produce stable, surfactant- and contamination-free colloidal NP solutions that are suitable for applications in various fields including biomedicine [5] [7, catalysis [8 11], and plasmonics [12 14]. The ability to synthesize metal and semiconductor NPs in a single step at room temperature in water gives PLAL a major advantage over conventional wet chemical synthesis approaches [2 4, 15, 18. In addition to the simple procedures and ambient conditions used to synthesize NPs via PLAL, the highly nonequilibrium conditions created in the ablation plasma and at its interface with the liquid environment can result in metastable phases and NPs possessing unique structures, shapes, and compositions such as nanocubes [19, 20], nanodiamonds [21], and thermodynamically metastable crystal structures of $\mathrm{TiO}_{2}$ [22], Si [23], and $\mathrm{Ge}$ [24].

A second laser-assisted approach to metal NP synthesis involves photochemical reduction of metal salts by focusing the laser beam into solution [25]. The dense plasma formed at the laser focus in solution generates a high concentration of reactive species such as hydrated electrons and hydrogen radicals [26], which can reduce metal salts to form isolated metal atoms that coalesce into NPs. Laser-mediated photochemical reduction has been widely used to synthesize $\mathrm{Au}$ [27 35], Ag [36 38, and multiple types of metal alloy 39 42] NPs. Like PLAL, laser photochemical reduction can produce sub-5 nm Au NPs at room temperature in aqueous solution without added surfactants or stabilizers

30, 31. Laser photochemical reduction is typically performed using laser pulses of picosecond [27-30] or femtosecond [31 34, 36-43] duration, although optical breakdown of water during micrometer-scale nanosecond UV laser irradiation 
has been identified [44, and Au NP synthesis with ns pulses at $532 \mathrm{~nm}$ was recently reported [43]. Femtosecond laser pulses form plasma primarily through photoionization instead of cascade ionization, which enables precise control over the plasma electron density by varying the laser peak intensity [26]. This ability to control reactive species formation rates with the peak intensity enables substantial control over Au NP size distributions [29, 31, 35, 43].

Recently, the approaches of PLAL and laser photochemical reduction have been combined into a single process through ablation of a solid target either immersed in or subsequently exposed to metal salt solution, in what is termed reactive laser ablation in liquid (RLAL) [10, 45 52]. RLAL has been widely used to generate metal-silica nanostructures, including $\mathrm{Si} / \mathrm{M}(\mathrm{M}=\mathrm{Ag}, \mathrm{Au}, \mathrm{Pd}$, Pt) core/shell NPs [47], Ag-core/silica-shell NPs [48, and large silica particles decorated with $\mathrm{Au}$ or $\mathrm{Ag}$ NPs [49]. While these RLAL reports have demonstrated the generation of hybrid semiconductor-metal nanocomposite materials in a single step, the metal-silica products are too large for catalysis applications such as CO oxidation that typically requires sub-5 nm metal NPs [53 56].

The current limited understanding of the exact timescales and locations of the chemical reactions occurring during RLAL poses challenges to further optimize the reaction conditions for tailoring the properties of the NP products for specific applications. Previous reports of RLAL use laser pulses of nanosecond duration, where it has been suggested that chemical reactions leading to NP formation occur during one or more of the following processes after the laser pulse is over [4]: plasma cooling on a timescale of $\sim 1 \mu \mathrm{s}$ [57], plasma mixing and cavitation bubble formation on a timescale of $\sim 0.1-1 \mu \mathrm{s}$ [58], and cavitation bubble collapse on a timescale of several hundred microseconds [59]. In contrast, a femtosecond laser plasma can form reactive species in solution within tens of femtoseconds [26], creating distinct reaction conditions for NP synthesis. The effects of such a different reaction environment on the resulting NP morphologies remain unexplored.

In this work, we report a RLAL approach where a Si wafer immersed in a $\mathrm{KAuCl}_{4}$ solution is ablated using sub-50 femtosecond (fs) laser pulses (fs-RLAL), 
producing significantly smaller silica-Au nanostructures than in previous reports using nanosecond lasers [47-49]. Using a high surface area support such as silica is commonly used to stabilize metal nanoparticles during catalytic reactions [60, 61]. The chemical and thermal stability of silica also allow for metal nanocatalysts to remain active for high temperature reactions such as $\mathrm{CO}$ oxidation 62. Additionally, its natural abundance makes it an economical option for fabricating catalytically active nanocomposite materials 60 63. The fs-RLAL technique used here generated two populations of silica-Au NPs: (i) isolated 7 $\mathrm{nm} \mathrm{Au} \mathrm{NPs,} \mathrm{and} \mathrm{(ii)} \mathrm{sub-3} \mathrm{nm} \mathrm{Au} \mathrm{NPs} \mathrm{stabilized} \mathrm{by} \mathrm{an} \mathrm{amorphous} \mathrm{silica} \mathrm{ma-}$ trix, which are catalytically active toward the reduction of para-nitrophenol by sodium borohydride. We discuss the formation of the two populations of silica$\mathrm{Au}$ NPs by the distinct timescales required for formation of reactive species in the plasma and from the silicon target.

\section{Materials and Methods}

\subsection{Materials}

Potassium tetrachloroaurate (III) $\left(\mathrm{KAuCl}_{4}\right.$, Strem Chemicals), potassium hydroxide (KOH, Fisher Scientific), silicon wafers ( $n$-doped, (111)-oriented, single side polished, $300 \mu \mathrm{m}$ thick, NOVA electronic materials), sodium borohydride ( $\mathrm{NaBH}_{4}$, Acros Organics), and para-nitrophenol (PNP, Acros Organics) were used as received. Water was purified by a Millipore Ultrapure water system and has a resistivity of $18.2 \mathrm{M} \Omega \mathrm{cm}^{-1}$ at $25^{\circ} \mathrm{C}$.

\subsection{Sample Preparation}

A working solution containing $\mathrm{KAuCl}_{4}(0.1 \mathrm{mM})$ and $\mathrm{KOH}(0.55 \mathrm{mM})$ was prepared from stock solutions ( $25 \mathrm{mM} \mathrm{KAuCl}_{4}$ and $\left.200 \mathrm{mM} \mathrm{KOH}\right)$, using Millipore Ultrapure filtered water. The working solution was prepared $18-24 \mathrm{hr}$ before carrying out experiments and stored at $6^{\circ} \mathrm{C}$. For each sample, $3.0 \mathrm{~mL}$ of the working solution was transferred to a $10 \times 10 \times 40 \mathrm{~mm}$ quartz fluorimeter cuvette containing a micro-stir bar (Fisher Scientific) and equilibrated to room 
temperature. The solution $\mathrm{pH}$ was measured to confirm it was $10.0 \pm 0.4$, and a pre-cut silicon wafer was placed inside the cuvette and secured against one side.

\subsection{Catalytic reduction of para-nitrophenol by sodium borohydride}

Catalytic test runs were carried out in a home-built in situ UV-vis spectrometer (details in section 2.4). In a typical catalytic reaction, a solution containing a final concentration of $0.1 \mathrm{mM}$ PNP and $10 \mathrm{mM}$ of freshly prepared $\mathrm{NaBH}_{4}$ was prepared. Prior to addition of the catalyst, the UV-vis absorbance of the para-nitrophenolate ion at $400 \mathrm{~nm}$ was monitored for about $20 \mathrm{~s}$ to confirm no reaction occurred in the absence of a catalyst. After the $20 \mathrm{~s}$ period, 0.50 $\mathrm{mL}$ of the as-synthesized silica-Au NP catalyst was added, initiating the reduction of PNP. The reaction was complete when the absorbance at $400 \mathrm{~nm}$ (para-nitrophenolate ion) had disappeared.

\subsection{Instrumentation}

Portions of the experimental setup have been described in detail in Refs. [31, 38. Briefly, 30 fs laser pulses were generated in a commercial Ti:Sapphire regenerative amplifier and attenuated to $50 \mu \mathrm{J}$ for the irradiation experiments. The silicon wafer in the cuvette was placed approximately $10 \mathrm{~mm}$ before the focal point of a $f=50 \mathrm{~mm}$ lens. The high-numerical aperture lens ensures that no filamentation occurs on the window of the cuvette or in the aqueous solution prior to interaction with the Si wafer (Fig. S1). The ablation spot size was $85 \mu \mathrm{m}$ in diameter based on the measurement of an ablated $\mathrm{Si}$ wafer with an optical microscope. Under these conditions, the laser fluence was $0.22 \mathrm{~J} \mathrm{~cm}^{-2}$ and peak intensity was $2.9 \times 10^{13} \mathrm{~W} \mathrm{~cm}^{-2}$.

The sample cuvette was placed on a miniature stir plate (Thermo Scientific) mounted to $\mathrm{x}$ - and $\mathrm{y}$ - motorized translation stages (Thorlabs). The stages were mounted on a manually controlled z-direction stage (Thorlabs), which was

adjusted to focus the laser beam onto the Si wafer (Fig. 1). The cuvette was translated in the $\mathrm{x}$ - and $\mathrm{y}$ - directions at a rate of $0.5 \mathrm{~mm} / \mathrm{s}$ during the irradiation experiments to move the laser focus across the $\mathrm{Si}$ wafer. UV-vis measurements 
were taken to confirm complete conversion of the precursor $\mathrm{KAuCl}_{4}$ solution to nanoparticles, with an irradiation time of 9 min required for complete conversion. UV-vis spectra of the sample after incremental laser irradiation times are displayed in Fig. S2a of the Supplemental Material.

The silica-Au NPs were centrifuged using a Fisher Scientific accuSpin Micro17 microcentrifuge. The as-synthesized sample was centrifuged for $30 \mathrm{~min}$ at 5,000 rpm, the pellet was washed with water and centrifuged for an additional $30 \mathrm{~min}$ at 5,000 rpm, then visualized using TEM and SEM.

For control samples containing no silicon wafer, $3.0 \mathrm{~mL}$ of the working solution was transferred to a cuvette containing a micro-stir bar and placed in a home-built in situ UV-vis spectrometer as described in ref. [31. Laser pulses were focused into the solution through a $f=50 \mathrm{~mm}$ lens, achieving a focal spot with a beam waist of $6.52 \mu \mathrm{m}$ (measured with a CCD camera, details reported in ref. [31]) yielding a fluence of $37.4 \mathrm{~J} \mathrm{~cm}^{-2}$ and an intensity of $1.25 \times 10^{15} \mathrm{~W}$ $\mathrm{cm}^{-2}$. In situ UV-vis measurements were collected to confirm full conversion of the $\mathrm{KAuCl}_{4}$ to AuNPs in 10 min (Fig. S2b in Supplemental Material).

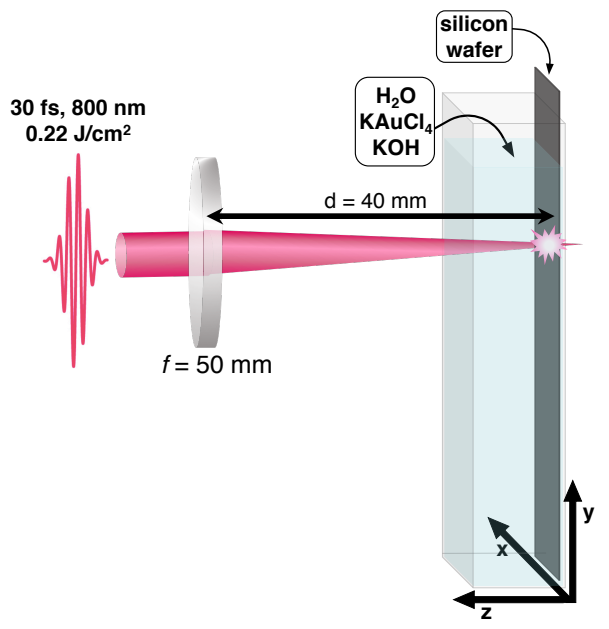

Figure 1: Experimental setup of laser pulses focused onto silicon wafer immersed in aqueous working solution.

The PNP catalytic reactions were carried out in second a home-built in situ 
UV-vis spectrometer consisting of a deuterium-tungsten lamp (Ocean Optics, DH2000-DUV), a sample holder for $10 \times 10 \times 40 \mathrm{~mm}$ cuvettes placed on a stir plate, and a compact spectrometer (Ocean Optics, USB4000) connected via optical fibers. Spectra were recorded once per 1.2 seconds using LabVIEW software (National Instruments). A figure of absorbance spectra of the PNP reaction over time is displayed in Fig. S3a in the Supplemental Material.

\subsection{Characterization}

Transmission Electron Microscopy (TEM). Samples were visualized using a JEOL JEM-1230 TEM at $120 \mathrm{kV}$, while high resolution TEM (HRTEM) imaging was carried out on a FEI Titan $300 \mathrm{kV}$ equipped with a Gatan 794 Multi-Scan Camera, a HAADF-STEM detector, and EDX Spectroscopy capabilities. The samples were drop-casted onto a carbon-coated grid (Ted Pella, Inc.) and left to dry for at least $24 \mathrm{hr}$ at room temperature. Average sizes and size distributions of the samples were measured using ImageJ software, which referenced 300 quasi-spherical particles from images of three separate areas on the TEM grid.

Scanning Electron Microscopy Energy Dispersive X-ray Spectroscopy (SEM$E D S$ ). Surface imaging and elemental analysis was conducted using a Hitachi FE SEM SU-70 (spatial resolution $1.0 \mathrm{~nm}$ ) equipped with an Energy Dispersive X-ray Spectroscopy (EDS) detector. Images were obtained at $10 \mathrm{keV}$ and elemental analysis was conducted at $20 \mathrm{keV}$. GENESIS Spectrum (EDAX) software was used to display EDS spectra and conduct elemental quantification using the ZAF algorithm. Samples were prepared by centrifuging the as-synthesized silica$\mathrm{Au}$ NPs (details in Section 2.4) and either pipetting the supernatant directly on conductive carbon tape (Ted Pella), or dispersing the centrifuged pellet in a few drops of ethanol (Fisher Scientific) and pipetting the solution onto conductive carbon tape and dried at room temperature under vacuum.

X-ray Diffraction (XRD). A PANalytical X'Pert PRO X-ray diffractometer equipped with a Ni-filtered $\mathrm{Cu} \mathrm{K} \alpha$ anode $(\mathrm{Cu}=0.15406 \mathrm{~nm})$ and a goniome- 
ter with a PIXel detector was used to obtain XRD patterns. A step size of $0.026^{\circ}$ was used at $300 \mathrm{sec}$ per step. Samples were prepared by drop casting the as-synthesized NPs onto a glass slide heated to $60^{\circ} \mathrm{C}$.

X-ray Photoelectron Spectroscopy (XPS). XPS spectra were collected on a Thermo Fisher ESCALab 250 with a monochromatized Al K $\alpha$ X-ray source (1486.6 eV) and a pass energy of $20 \mathrm{eV}$. Charge neutralization was done by running an ion gun and a flood gun during sample analysis. The measurement spot diameter was $1 \times 0.5 \mathrm{~mm}$ with take off angle was $45^{\circ}$. Spectra were analyzed and deconvoluted using the Thermo Scientific Avantage Software, employing a Gaussian and Lorentzian convolution to fit the line profiles. All spectra were corrected based on the C1s peak shift to center at $284.8 \mathrm{eV}$. Samples were prepared by centrifuging as-synthesized NPs (13,000 rpm, 2 hr), and drying the collected pellets under vacuum at $60^{\circ} \mathrm{C}$. Powder samples were deposited on indium foil (ACROS Organics).

\section{Results and Discussion}

\subsection{Characterization}

The silica-Au NP and control Au NP samples were visualized using TEM, with representative images displayed in Fig. 2 and Fig. S4 in the Supplemental Material. The silica-Au NPs in Fig. 2 a show two distinct populations of particles; larger, often isolated particles (light blue arrow in Fig. 2a, "isolated particles") and small particles within a matrix (dark blue arrow in Fig. 2a, "stabilized particles"). The size distribution of the isolated particles was determined by counting particles that were separate from the silica matrix, yielding $7.0 \pm 2.0 \mathrm{~nm}$ (light blue histogram, Fig. 2. $)$. To measure the size distribution of the stabilized particles, the as-synthesized sample was centrifuged as described in Section 2.4. Figure 2b shows a TEM image of the centrifuged pellet, where the small Au NPs remain dispersed within the silica matrix (dark blue arrow in Fig. 2b), while isolated $\mathrm{Au}$ NPs that were not removed during centrifugation agglomerated to form a chain-like structure (light blue arrow in Fig. 2p). In 
the centrifuged pellet, only particles visually found within the silica matrix were counted to obtain the size distribution of $1.9 \pm 0.7 \mathrm{~nm}$ (dark blue histogram, Fig. 2F). The control Au NPs in Fig. 2e were larger and more polydisperse, having a mean diameter of $9.3 \pm 4.6 \mathrm{~nm}$ (Fig. 2f), and several nanotriangles were visible as well.

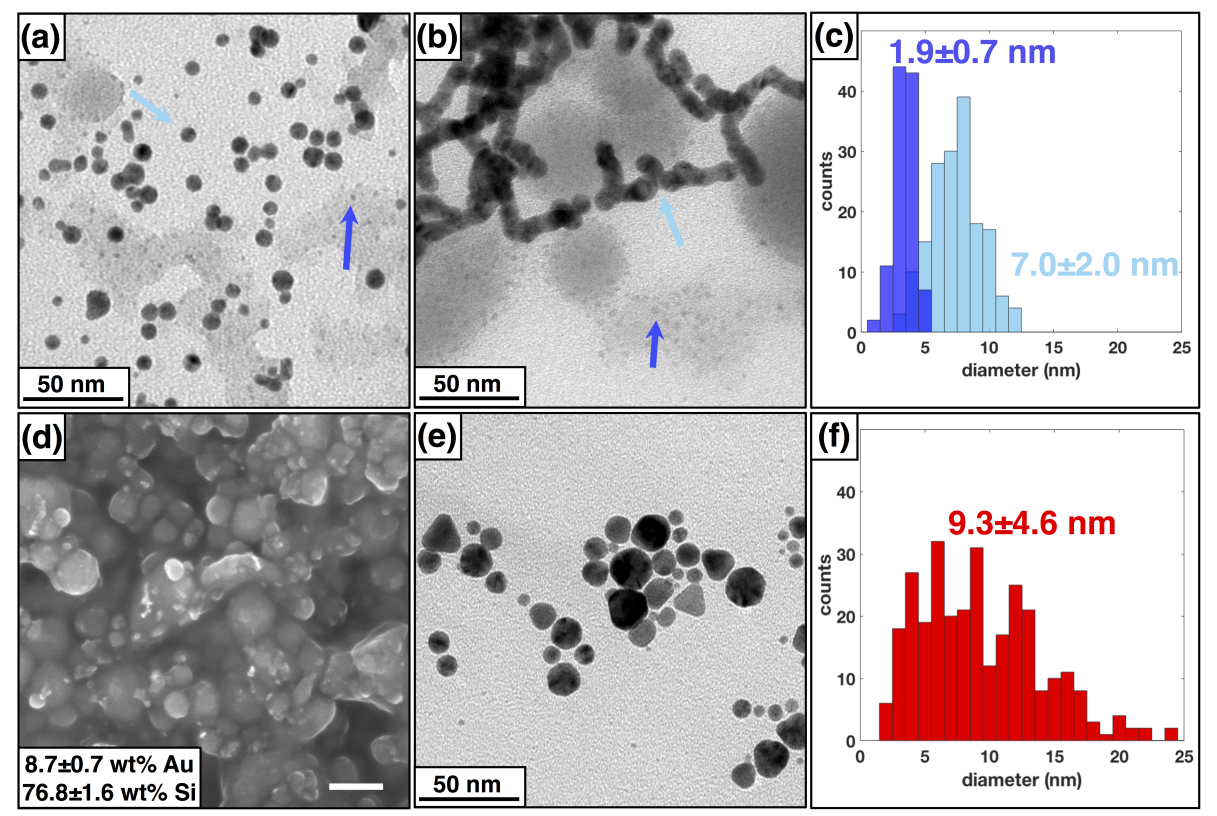

Figure 2: TEM image of as-synthesized (a) and centrifuged pellet (b) silica-Au NPs. Size distribution of as-synthesized silica-Au NPs (c). SEM image with EDS quantification of Si and $\mathrm{Au}$ in centrifuged pellet silica-Au NPs; scale bar represents $200 \mathrm{~nm}$ (d). TEM image of control Au NPs (e) with size distribution (f).

SEM-EDS was used to visualize the surface morphology of the sample and quantify the $\mathrm{Au}$ and $\mathrm{Si}$ present in the supernatant and centrifuged pellet portions of the silica-Au NP sample. Figure 2d shows an SEM image of the centrifuged pellet, showing many spherical grey particles and amorphous structures decorated with white edges. Since the sample was not sputter-coated prior to imaging it is unclear whether the white portion of the image is due to the conductive Au present, or due to charging of the non-conductive silica. However, EDS analysis of the sample detected some gold (8.7 wt\%) and mostly silicon 
(76.8 wt\%), while the remainder of the sample contained oxygen (not reported). The supernatant contained more gold than the pellet did, with $44.6 \mathrm{wt} \% \mathrm{Au}$ and $12.3 \mathrm{wt} \% \mathrm{Si}$ (Fig. S6a in the Supplemental Material, oxygen not reported). Control silica NPs were also analyzed with SEM-EDS, revealing similar surface morphology to the silica-Au NPs, and a small amount of gold present in the sample, likely from contamination in the cuvettes used (0.36 wt\% Au, $89.2 \mathrm{wt} \%$ Si, Fig. S6b in Supplemental Material).

HRTEM analysis (Fig. 3a) shows polycrystalline particles, with lattice spacings corresponding to fcc-Au. Both populations of the silica-Au NPs are polycrystalline, as shown in the inset of the HRTEM in Fig. 3a. The spacings were measured to be $2.32 \AA, 2.10 \AA$, and $1.45 \AA$, corresponding to the (111), (200), and (220) planes of fcc-Au. The matrix containing the small Au NPs appears to be amorphous, since no lattice spacings were observed. The control Au NPs were also polycrystalline, with the $2.44 \AA, 2.35 \AA$, and $1.39 \AA$ spacings corresponding to the (111) and (220) planes of fcc-Au. The fast Fourier transform (FFT) of the Au NPs within the red square of Fig. 3p confirms the fcc-Au pattern.
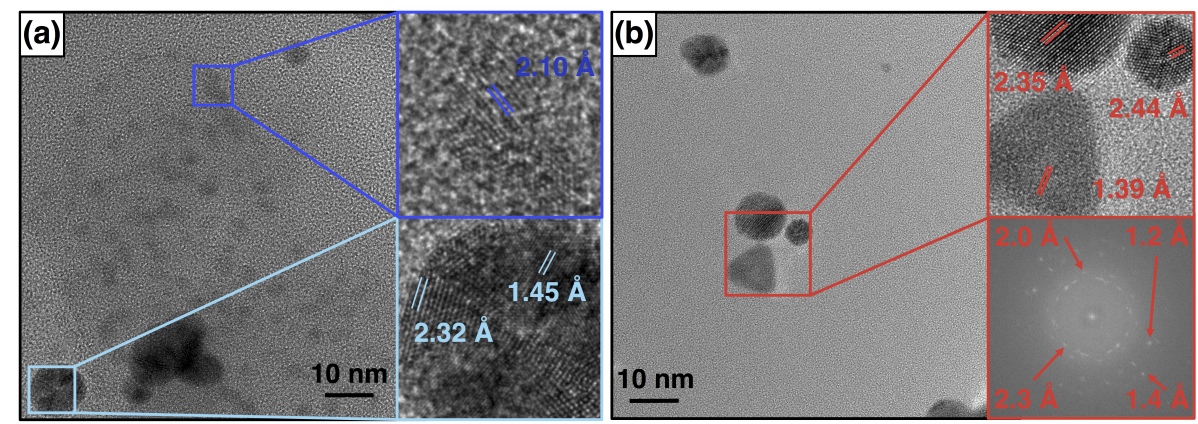

Figure 3: HRTEM image with lattice spacings for silica-Au NPs (a) and HRTEM image, lattice spacings and FFT of control Au NPs (b).

HAADF-STEM images of the silica-Au NPs revealed white spheroid particles and grey amorphous material, corresponding to gold and silica, respectively. Due to the significantly different atomic numbers between gold and silicon, it 
is possible to visually identify the two elements: the higher atomic number element has higher contrast (gold $=$ white) than the lower atomic number element $($ silicon $=$ grey $)$ 47]. The EDX spectrum in Fig. 4a taken of an isolated Au NP (white particle) inside the red circle shows the presence of both Si and Au. While the area in the red circle appears to be all white, corresponding to $\mathrm{Au}$, the Si detected could either be from surrounding $\mathrm{Si}$ in the matrix, or due to interstitial Si atoms within the Au crystal lattice. Since the XRD patterns of the silica-Au NPs and the control Au NPs match (Supplemental Material, Fig. S5), it is likely that the Si detected with EDX is predominantly from the amorphous silica near the free Au NP, although small amounts of interstitial Si in the Au NPs cannot be ruled out. In Fig. 4b, the EDX spectrum of a barely visible light particle inside the red circle contains mostly silicon and a small amount of gold, indicative of a small Au NP stabilized by a large amount of silica. This result is consistent with the small particles visible in the TEM images in Fig. $2 \mathrm{a}$ and $3 \mathrm{a}$ of small Au NPs stabilized by a silica matrix.

The XPS spectra from the Au4f, Si2p, and O1s atomic orbitals for the silica$\mathrm{Au}$ NPs, control Au NPs, and control silica NPs generated from ablating a silicon wafer in water are displayed in Fig. 55 the suggested species, deconvoluted peak binding energies, and atomic percentages of the species are presented in Table 1. The Au4f spectra reveal both neutral $\mathrm{Au}^{0}$ and oxidized surface $\mathrm{Au}$ atoms in the silica-Au NPs and control Au NPs. The $84.0 \mathrm{eV}$ binding energy corresponds to bulk $\mathrm{Au}^{0}$, while peaks at slightly lower binding energy near 83 $\mathrm{eV}$ represent low coordinated $\mathrm{Au}^{0}$ atoms [64 66]. The control Au NP sample contained significantly more low coordinated $\mathrm{Au}^{0}$ atoms than the silica-Au NP sample. The peak around $85 \mathrm{eV}$ corresponds to partially oxidized Au atoms or low coordinated $\mathrm{Au}^{1+}$ atoms $\left(\mathrm{Au}^{1+}\right)$ in Fig. 5 and Table 1 [65. In addition to the $\mathrm{Au}^{1+}$ species, a peak at $85.8 \mathrm{eV}$ was deconvoluted in the silica-Au NPs only, corresponding to $\mathrm{Au}^{3+}$ as $\mathrm{Au}_{2} \mathrm{O}_{3}$ surface oxide species [67]. This oxidation state was not deconvoluted in the control Au NP sample.

The Si2p spectrum for the silica-Au NPs in Figure $5 \mathrm{~b}$ contains the expected peaks at $103.5 \mathrm{eV}$ for $\mathrm{SiO}_{2}[68+70]$ and $99.4 \mathrm{eV}$ for $\mathrm{Si}^{0}$ [68 70 , with an additional 

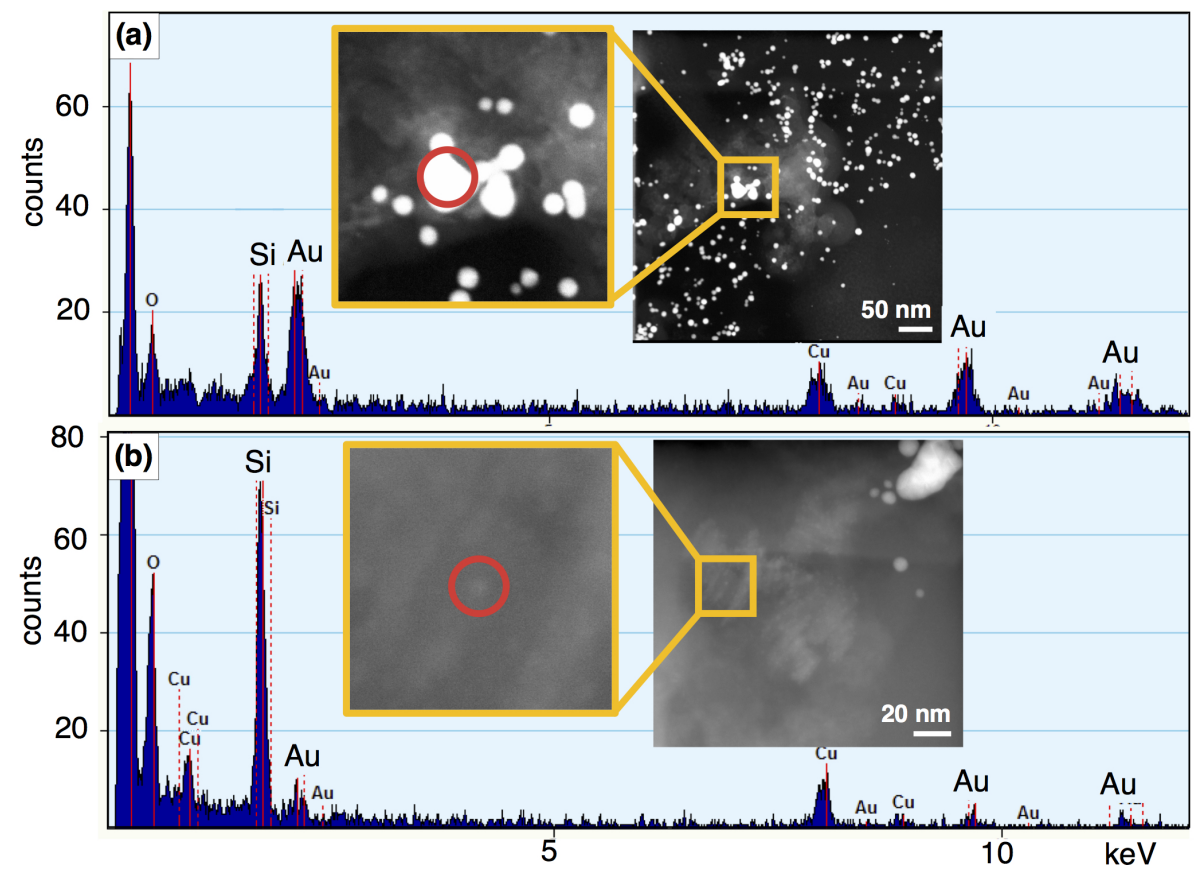

Figure 4: HAADF-STEM image of silica-Au NPs with EDX spectrum taken of portion inside red circle. 
peak at $98.0 \mathrm{eV}$, which has not been previously reported. Due to its proximity to the neutral $\mathrm{Si}^{0}$ species, the peak at $98.0 \mathrm{eV}$ is most likely in the form of $\mathrm{Si}^{1-}$, since the $\mathrm{Si}^{1+}$ is shifted up by $\sim 1 \mathrm{eV}$ from the $\mathrm{Si}^{0}$ peak [69]1]. The presence of this putative $\mathrm{Si}^{1-}$ species is surprising due to the electropositive nature of $\mathrm{Si}$, but the accessibility of metastable phases in the nonequilibrium environment formed at the plasma-water interface [3, 14, 47, 72] could enable the formation of such exotic species. The large peak centered around $103.5 \mathrm{eV}$ in the silica-Au NPs was deconvoluted into two peaks, which are likely two types of silica species with different electronic structures [68, 73], or silicon species with different oxide layer thicknesses [69, 74]. The more abundant peak at $102.9 \mathrm{eV}$ could be a thin oxide layer [69, or it could be bound with gold particles, as reports with silica and colloidal Au may have a slightly lower binding energy to silica alone [68]. The peak at $104.6 \mathrm{eV}$ is on the higher range of binding energies for silica, which could be due to a thicker oxide layer in the matrix or the presence of large silica particles [69, 74], based on a recent report of $104.3 \mathrm{eV}$ binding energy of a 200 $\mathrm{nm}$ thick layer of silica [74]. Alternatively, the higher binding energy peak may arise from quartz based on previous XPS studies [68, 75]. The control silica NPs synthesized in water contain the same peaks in the Si2p spectrum, confirming that these species are formed from laser ablation of the silicon wafer in liquid, regardless of the presence of metal salt. A small peak $(2 \%)$ corresponding to $\mathrm{Si}^{1+}$ 69 71] was also present in the control silica NPs; the other peaks are shifted to slightly higher binding energies compared to the silica-Au NPs. This could also be due to the general oxide layers being thicker [69, 74], or due to the absence of Au NPs 68. Gross et al. studied binding energy shifts of silica with and without colloidal gold, and found that with quartz species, the Si2p binding energy shifted down slightly when colloidal gold was present, while silica gel exhibited no binding energy shift whether the gold was present or not 68]. TEM, HRTEM, FFT and lattice spacing measurements of the control silica NPs (Fig. S7 of the Supplemental Material) show two populations of silica: amorphous and polycrystalline particles. This reflects the two deconvoluted peaks in the Si2p spectrum, although it is difficult to assign peaks to the different 
morphologies, due to overlapping binding energies reported for the different silica species [68, 73, 74, 76, 77]. The weak Si2p signal in the control Au NP sample may be partially oxidized Si species arising from contamination from the quartz cuvette used for irradiation experiments.

The O1s spectra in Fig. 5s show that most of the O1s surface species in the silica-Au NPs is from silica [73, 78, and a small percentage from oxidized gold $\left(\mathrm{Au}_{2} \mathrm{O}_{3}\right.$ and $\left.\mathrm{Au}(\mathrm{OH})_{3}\right)$ [79]. The binding energy assigned to $\mathrm{SiO}_{2}$ at 532.6 $\mathrm{eV}$ matches closely to that reported by Gross et al. for quartz with colloidal gold $(532.7 \mathrm{eV})$, and is close to the reported value for crystalline quartz [80]. Although the HRTEM image for the silica-Au NPs (Fig. 3a) does not contain any crystalline silica species, XPS analysis can identify species not visible with electron microscopy imaging. The control Au NPs contain mostly oxidized gold species, corresponding to surface hydroxides. The binding energy at $531.3 \mathrm{eV}$ is close to that of $\mathrm{Au}(\mathrm{OH})_{3}\left[79\right.$, giving the surface gold atoms a $\mathrm{Au}^{3+}$ oxidation state that was not detected in the Au4f spectrum for the control Au NPs. Partial oxidation of the gold surface atoms is likely the case. Three peaks were deconvoluted in the control silica NPs O1s spectrum, with a small (1\%) amount corresponding to that of amorphous silica [80, and the other two in the range of silica species [68, 69, 74, 77, 78]. The peak at $532.8 \mathrm{eV}$ closely matches reported binding energy values for quartz $(532.7 \mathrm{eV}[80])$, while the majority of the O1s signal comes from the peak deconvoluted at $533.1 \mathrm{eV}$, which is close to the $533.2 \mathrm{eV}$ binding energy reported for silica [68, 69, 74, 77, 78]. It is difficult to assign species based on the Au4f, Si2p, and O1s XPS spectra due to overlapping binding energies reported. However, we hope to demonstrate the multiple types/populations of silica generated from our fs-RLAL approach.

The Cl2p binding energies are presented in Table 1 and the spectra are displayed in the Supplemental Material, Fig. S8. The peaks correspond to metal chlorides, likely from the $\mathrm{KAuCl}_{4}$ precursor [78]. 


\begin{tabular}{|c|c|c|c|c|}
\hline Species & silica-Au NPs & $\mathrm{Au} \mathrm{NPs}$ & $\mathrm{SiO}_{2} \mathrm{NPs}$ & bulk (reference) \\
\hline low coord. $\mathrm{Au}^{0}$ & $82.9 ; 7 \%$ & $82.8 \mathrm{eV} ; 30 \%$ & & $83.3 \mathrm{eV} 64-66$ \\
\hline $\mathrm{Au}^{0}$ & $83.8 \mathrm{eV} ; 72 \%$ & $84.0 \mathrm{eV} ; 55 \%$ & & $84.0 \mathrm{eV}$ [64, 66, 76] \\
\hline $\mathrm{Au}^{1+}$ & $84.9 ; 13 \%$ & $85.2 \mathrm{eV} ; 15 \%$ & & $85.2 \mathrm{eV} 65$ \\
\hline $\mathrm{Au}^{3+}$ & $85.8 ; 8 \%$ & & & $85.8 \mathrm{eV} 67$ \\
\hline $\mathrm{Si}^{1-*}$ & $98.0 ; 11 \%$ & & $98.3 ; 13 \%$ & \\
\hline $\mathrm{Si}^{0}$ & $99.4 ; 8 \%$ & & $99.8 ; 6 \%$ & $99.4 \mathrm{eV} 68$ \\
\hline $\mathrm{Si}^{1+}\left(\mathrm{Si}_{2} \mathrm{O}\right)$ & & & $100.9 ; 2 \%$ & $100.5 \mathrm{eV} 69-71$ \\
\hline $\mathrm{Si}^{3+}\left(\mathrm{Si}_{2} \mathrm{O}_{3}\right)$ & & $101.9 ; 100 \%$ & & $102 \mathrm{eV}$ [69] \\
\hline $\mathrm{Si}^{4+}\left(\right.$ thin $\left.\mathrm{SiO}_{2}\right)$ & $102.9 ; 69 \%$ & & $103.4 ; 64 \%$ & $102.6-104 \mathrm{eV}$ 68 $70,77,81$ \\
\hline $\mathrm{SiO}_{2}$ (thick/quartz) & $104.6 ; 12 \%$ & & $105.4 ; 15 \%$ & \\
\hline $\mathrm{Au}_{x} \mathrm{O}_{y}$ & & $529.0 ; 2 \%$ & & $529-530 \mathrm{eV}[79$ \\
\hline $\mathrm{Au}_{2} \mathrm{O}_{3}$ & $529.8 ; 1 \%$ & $530.5 ; 5 \%$ & & $530.2 \mathrm{eV}[79$ \\
\hline $\mathrm{Au}_{\mathrm{x}}(\mathrm{OH})_{\mathrm{y}}$ & $531.2 ; 9 \%$ & $531.3 ; 93 \%$ & & $531.2 \mathrm{eV}^{a} 79$ \\
\hline $\mathrm{SiO}_{2}$ (amorphous) & & & $530.7 ; 1 \%$ & $530.7 \mathrm{eV} 80$ \\
\hline $\mathrm{SiO}_{2}$ (quartz) & $532.6 ; 90 \%$ & & $532.8 ; 5 \%$ & $532.9 \mathrm{eV}[68,78$ \\
\hline $\mathrm{SiO}_{2}$ & & & $533.1 ; 94 \%$ & $533.2-534 \mathrm{eV}[68,73,74,77,78$ \\
\hline $\mathrm{Au}-\mathrm{Cl}$ & $199 \mathrm{eV} ; 100 \%$ & $198.5 \mathrm{eV} ; 100 \%$ & & $198.8-199.2 \mathrm{eV} ; 78]^{b}$ \\
\hline
\end{tabular}

Table 1: Binding energy (eV) and atomic percent of various species deconvoluted from XPS analysis. Binding energy values correspond to $\mathrm{Au} 4 \mathrm{f}_{7 / 2}, \mathrm{Si}_{2} \mathrm{p}_{3 / 2}, \mathrm{O} 1 \mathrm{~s}$, and $\mathrm{Cl} 2 \mathrm{p}_{3 / 2}$ peaks. ${ }^{*}$ Suggested species not reported in literature. ${ }^{a}$ value reported for $\mathrm{Au}(\mathrm{OH})_{3} .{ }^{b}$ binding energies reported for transition metal chloride compounds. 


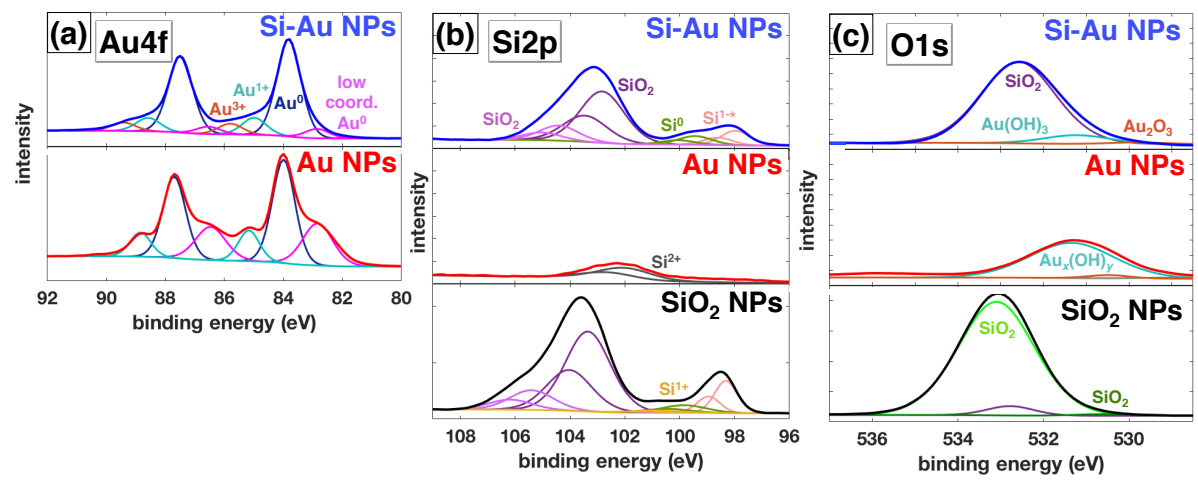

Figure 5: XPS spectra for Au4f (a), O1s (b), Si2p (c) atomic orbitals for silica-Au NPs (blue), $\mathrm{Au}$ NPs (red), and silica NPs (black) with fitted peaks.

\subsection{Catalysis}

The reduction reaction of PNP by sodium borohydride was used to test the catalytic activity of the silica-Au NPs. This is a common model reaction that can be easily monitored via UV-vis spectroscopy by the decrease in absorbance of the para-nitrophenolate ion at $400 \mathrm{~nm}$, allowing for direct extraction of the pseudo-first-order rate constant [82, 83]. The PNP reduction reaction follows a two-step mechanism involving (i) the diffusion and adsorption of PNP to Au surfaces, and (ii) electron transfer mediated by the $\mathrm{Au}$ surface from $\mathrm{BH}_{4}{ }^{-}$to PNP [61, 84, 85]. Therefore, designing Au nanocatalysts with high surface areas (small NP size) and available surface sites are expected to increase the catalytic activity. Experimental details and associated rate equations used to extract the rate constants reported below are provided in the Supplemental Material.

Table 2 displays the size, specific surface area (SSA), and catalytic rate constants comparing the silica-Au NPs and the control Au NPs synthesized in this work. The $6.17 \mathrm{~nm}$ diameter of the Au NPs in the silica-Au NP sample was weighted by assigning the Au quantified from SEM-EDS analysis of the centrifuged pellet to the stabilized Au NPs (1.9 nm, $8.7 \mathrm{wt} \%)$, and the amount of $\mathrm{Au}$ detected in the supernatant to the isolated particles $(7.0 \mathrm{~nm}, 44.6 \mathrm{wt} \%)$. Calculations for the weighted mean diameter and other values reported in Table 
2 are provided in the Supplemental Material.

The $k_{A u}$ rate constant is normalized to the moles of $\mathrm{Au}$ added to the experiment, reflecting the efficiency of $\mathrm{Au}$ atoms present in the nanocatalysts independent of the size dispersity, while the SSA-normalized rate constant $k_{1}$ depends on available surface sites driving the PNP reaction. When the $k_{A u}$ rate constant is considered, the silica-Au NPs are much more catalytically active compared to the control Au NPs, showing higher efficiency of the Au atoms in the sample. However, when the SSA of the samples is normalized, the $k_{1}$ rate constant of the silica-Au NP sample is not significantly different than the control Au NPs. This reflects the inert chemical behavior of the silica support material, which is not expected to enhance the catalytic activity of the silica-Au NPs [60, 61].

\begin{tabular}{|c|c|c|}
\hline Property & silica-Au NPs & control Au NPs \\
\hline size $(\mathrm{nm})$ & $6.17^{a}$ & $9.3 \pm 4.6$ \\
$k_{A u}\left(\mathrm{~s}^{-1} \mu \mathrm{mol}^{-1}\right)$ & $0.104 \pm 0.013$ & $0.067 \pm 0.011$ \\
$\mathrm{SSA}\left(\mathrm{m}^{2} \mathrm{~L}^{-1}\right)$ & $0.97^{b}$ & 0.64 \\
$k_{1}\left(\mathrm{~s}^{-1} \mathrm{~L} \mathrm{~m}^{-2}\right)$ & $0.0053 \pm 0.0007$ & $0.0051 \pm 0.0009$ \\
\hline
\end{tabular}

Table 2: Summary of nanoparticle size, specific surface area (SSA), and rate constants. ${ }^{a}$ Weighted mean diameter calculated using $1.9 \mathrm{~nm}$ stabilized and $7.0 \mathrm{~nm}$ isolated Au NPs; weighted amounts taken from wt \% quantified using SEM-EDS. ${ }^{b}$ SSA calculated using 6.17 $\mathrm{nm}$ weighted mean diameter of Au NPs. Calculations provided in Supplemental Material.

\subsection{Reaction Timescales}

To explain the formation of two populations of silica-Au NPs in fs-RLAL, we consider the timescales of chemical reactions in the initially generated plasma and material ejection from the Si wafer occurring in our experiments. Due to the extremely short duration of the femtosecond laser pulse as compared to the nanosecond pulses typically used in RLAL, both plasma reactions and material ejection can occur on significantly faster timescales than the $\sim \mu$ s timescales of cavitation bubble formation and collapse. Here, we will focus on how these early 
reactions taking place on timescales of tens of femtoseconds through nanoseconds can form two types of silica-Au NPs.

We first consider reactions in the initially formed plasma at the water-Si interface. The laser intensity used in our experiments exceeds the optical breakdown (OB) threshold of $10^{13} \mathrm{~W} \mathrm{~cm}^{-2}$ for $800 \mathrm{~nm}, 30 \mathrm{fs}$ pulses in water [26], and the fluence is sufficient to produce an electron-hole pair density at the $\mathrm{Si}$ surface exceeding the critical threshold of $10^{22} \mathrm{~cm}^{-3}$ for ablation [86, 87]. The electrons generated in the OB plasma (eq $1-3)$ and ejected from the Si surface can induce $\mathrm{Au}^{3+}$ reduction (eq 5). The timescales for both electron formation processes are on the order of a few tens of femtoseconds [14, 86 89], and the resulting electrons become hydrated (eq 2 on a timescale of several hundred femtoseconds [90, 91]. Because hydrated electrons react with $\left[\mathrm{AuCl}_{4}\right]^{-}$with a diffusion-controlled rate constant of $6.1 \times 10^{10} \mathrm{M}^{-1} \mathrm{~s}^{-1}[92]$ and have a lifetime in pure water of hundreds of $\mathrm{ns}\left[93,\left[\mathrm{AuCl}_{4}\right]^{-}\right.$reduction in solution can begin within hundreds of femtoseconds of the laser pulse and occur during the next several ns. As a result, a significant fraction of the available $\left[\mathrm{AuCl}_{4}\right]^{-}$near the laser focus may be consumed within $\sim 1$ ns of the laser pulse. The OB plasma also contains $\mathrm{OH}$ radicals that lead to the formation of $\mathrm{H}_{2} \mathrm{O}_{2}$ (eq 4 ) on the timescale of $\sim 10 \mathrm{~ns}-10 \mu \mathrm{s}$ [93. This peroxide formation induces autocatalytic surface growth of the gold clusters to larger nanoparticles (eq 6] [28, 30, 31]. We propose that this plasma-mediated mechanism beginning within tens of femtoseconds following arrival of the laser pulse drives the formation of the larger isolated $\mathrm{Au}$ NPs in our experiments. 


$$
\begin{aligned}
& \mathrm{H}_{2} \mathrm{O} \stackrel{n h \nu}{\longrightarrow} \mathrm{e}^{-}+\mathrm{H}^{+}+\mathrm{OH} \cdot \\
& \mathrm{e}^{-} \longrightarrow \mathrm{e}_{\mathrm{aq}}^{-} \\
& \mathrm{H}_{2} \mathrm{O} \stackrel{n h \nu}{\longrightarrow} \mathrm{H} \cdot+\mathrm{OH} \cdot \\
& 2 \mathrm{OH} \cdot \longrightarrow \mathrm{H}_{2} \mathrm{O}_{2} \\
& {\left[\mathrm{AuCl}_{4}\right]^{-}+3 \mathrm{e}_{\mathrm{aq}}^{-} \longrightarrow \mathrm{Au}(0)+4 \mathrm{Cl}^{-}} \\
& {\left[\mathrm{AuCl}_{4}\right]^{-}+\frac{3}{2} \mathrm{H}_{2} \mathrm{O}_{2}+\mathrm{Au}_{m} \longrightarrow \mathrm{Au}_{m+1}+\frac{3}{2} \mathrm{O}_{2}+3 \mathrm{HCl}+\mathrm{Cl}^{-}}
\end{aligned}
$$

Second, we consider the dynamics of material ejection from the Si surface. After the removal of free electrons, a strong electrostatic field develops on the Si surface due to the charge separation, which ultimately pulls out silicon atoms and ions from the surface if the laser fluence is above the ablation threshold [86 88. Our fluence of $0.22 \mathrm{~J} \mathrm{~cm}^{-2}$ exceeds the reported ablation threshold for $\mathrm{Si}$ in water with $<100 \mathrm{fs}$ laser pulses $\left(\sim 0.16 \mathrm{~J} \mathrm{~cm}^{-2}[94)\right.$ by a factor of $\sim 1.4$. At fluences up to $\sim 3$ times the ablation threshold, both experiments and molecular dynamics simulations report the beginning of material ejection on a timescale of tens or hundreds of ps after the laser pulse, depending on the target material and environmental conditions (Table 3) [14, 72, 86, 89, 95]. While reported timescales for Si ejection are typically faster than 100 ps [86, 89, 95], these studies were conducted in air or vacuum, without the confinement provided by the water environment. The slower timescales of 200-500 ps reported for Ag in water [14, 72] likely provide a better estimate for the ejection of $\mathrm{Si}$ atoms into the surrounding water in our experiments. Subsequent ejection of larger molten droplets can then occur on timescales of several ns [14]. These Si species in the expanding low-density Si-water mixing region or injected into the colder water above will undergo rapid oxidation and cooling, and can provide nucleation sites for nearby gold ions. We propose that the ejection of Si species on the sub-ns timescale leads to formation of the stabilized silica-Au NPs. The small size of the Au NPs stabilized by the silica matrix may result from either depleted $\left[\mathrm{AuCl}_{4}\right]^{-}$concentration due to the plasma reactions discussed above or silica 
species coalescing around the initially formed Au nuclei, halting further growth.

\begin{tabular}{|c|c|c|c|}
\hline material & pulse duration $(\mathrm{fs})$ & environment & timescale $(\mathrm{ps}) /$ Ref \\
\hline $\mathrm{Si}$ & 130 & air & $20-100[86]$ \\
$\mathrm{Si}$ & 500 & vacuum & $25[95]$ \\
$\mathrm{Si}$ & 90 & air & $10-100[89]$ \\
$\mathrm{Ag}$ & 40 & water & $200[72]$ \\
$\mathrm{Ag}$ & $10^{4}$ & water & $500[14]$ \\
\hline
\end{tabular}

Table 3: Reported timescales for onset of material ablation with femtosecond pulses.

The proposed reactions and timescales in our experiments that lead to each population of silica-Au NPs are illustrated in Fig. 6. At early times during and immediately after the pulse, the plasma reactions begin. Free electrons generated in the plasma at the Si-water interface hydrate and react with the initially high concentration of $\left[\mathrm{AuCl}_{4}\right]^{-}$, forming Au nuclei within hundreds of fs to a few ns. These can coalesce and react with the $\mathrm{H}_{2} \mathrm{O}_{2}$ generated beginning around 10 ns to predominantly form the larger isolated Au NPs. Meanwhile, surface reactions begin around 100 ps or later. The ejected Si atoms and liquid droplets oxidize and coalesce, at which point they can react with the remaining $\left[\mathrm{AuCl}_{4}\right]^{-}$and $\mathrm{Au}$ nuclei present. The expected low concentration of $\left[\mathrm{AuCl}_{4}\right]^{-}$ near the Si-water interface at around $1 \mathrm{~ns}$ after the laser pulse could give rise to the predominant formation of ultrasmall Au NPs stabilized by the Si that is ejected. Alternatively, the encapsulation of the growing Au nanoclusters by the Si species could quench the growth. The presence of some large Au NPs that appear to be attached to the Si matrix (Fig. 2a) may be accounted for by $\mathrm{Au}$ NPs formed in the plasma reactions coming into contact with the Si species prior to their cooling. Finally, we note that the formation of cavitation bubbles beginning approximately $100 \mathrm{~ns}$ after the laser pulse [58] could contribute to the observed silica-Au NP morphologies, particularly for the stabilized Au NPs.

Both the isolated and embedded silica-Au NPs formed in our experiments have significantly different morphologies as compared to silica-Au NPs prepared 


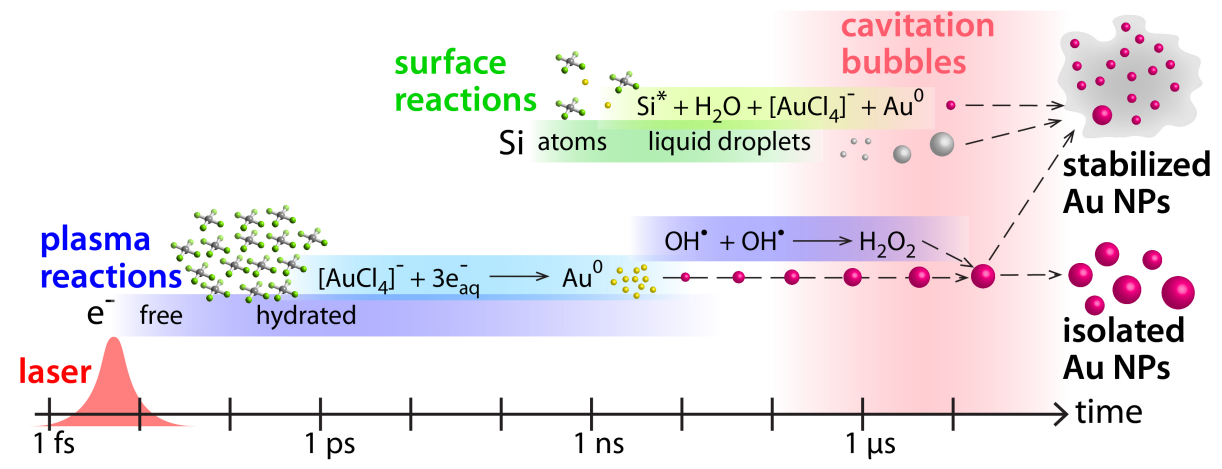

Figure 6: Proposed timescales of reactions in fs-RLAL.

from ns-RLAL, indicating that completely different reaction dynamics from those depicted in Fig. 6 occur when ns lasers are used. Saraeva et al. generated small $\sim 10 \mathrm{~nm} \mathrm{Au} \mathrm{NP-decorated} \sim 1 \mu \mathrm{m}$ silica particles from ns-RLAL of a silicon wafer immersed in a $\left[\mathrm{AuCl}_{4}\right]^{-}$solution [49]. They reported that no $\mathrm{Au}$ NPs formed in the absence of the Si wafer, indicating that $\left[\mathrm{AuCl}_{4}\right]^{-}$reduction occurred primarily through reaction with ablated Si species through processes such as galvanic replacement [49]. In contrast, the formation of Au NPs from plasma reactions in water alone indicates that $\left[\mathrm{AuCl}_{4}\right]^{-}$reduction in fs-RLAL can occur without any Si species interactions, as we propose in Fig. 6. Liu et al. employed a double beam ns-RLAL approach using a $355 \mathrm{~nm}, 2 \mathrm{~ns}$ pulse for ablation and a $532 \mathrm{~nm}, 10 \mathrm{~ns}$ pulse to irradiate the ablation plasma, resulting in large silica particles $(\sim 200-500 \mathrm{~nm})$ possessing wrinkled surfaces, silica particles with veins of gold throughout, and silica-core/Au-shell particles [47]. They reported that irradiation of the the plasma region at a wavelength resonant with the $\mathrm{Au}$ SPR frequency facilitated the reduction of $\left[\mathrm{AuCl}_{4}\right]^{-}$to form $\mathrm{Au}$ NPs that encapsulate the ejected Si species [47]. The simultaneous material ejection and metal salt reduction timescales over hundreds of ns in the latter experiments are distinct from the likely separate timescales of metal salt reduction and material ejection that can occur in fs-RLAL. Further investigation of the different nanoparticle formation mechanisms in ns- and fs-RLAL is needed to fully understand the origin of the distinct particle morphologies produced. 


\section{Conclusions}

This work introduced a fs-RLAL approach as a facile route to silica-Au NPs with significantly smaller Au NP sizes than accessible in previously reported ns-RLAL studies. The silica-Au NPs were found to be active towards catalytic reduction of PNP by $\mathrm{NaBH}_{4}$, with similar surface area normalized activity when compared to the control Au NPs synthesized in the absence of Si. Characterization of the products revealed two populations of Au NPs- (i) larger, predominantly isolated Au NPs $(7.0 \pm 2.0 \mathrm{~nm})$, and (ii) small Au NPs $(1.9 \pm 0.7$ $\mathrm{nm}$ ) stabilized by an amorphous silica matrix, along with previously unreported silica species deconvoluted in the Si2p XPS spectra. Considering the timescales of reactions in a fs-laser optical breakdown plasma and material ejection from ablation, we proposed formation mechanisms for the two observed populations of silica-Au NPs. Unlike in ns-RLAL, we expect that photochemical reduction of metal ions can occur before material ejection in fs-RLAL, potentially enabling unprecedented control over accessible particle morphologies due to the separation of the reduction and ablation steps. Further elucidation of the distinct chemical reactions and timescales occurring in ns- and fs-RLAL is needed to advance the rational design and synthesis of catalytically active nanostructures using this readily generalizable approach.

\section{Acknowledgement}

This work was supported by the American Chemical Society Petroleum Research Fund (57799-DNI10) and Virginia Commonwealth University. Microscopy was performed at the VCU Department of Anatomy and Neurobiology Microscopy Facility, supported by the Higher Education Equipment Trust Fund

Grant No. 236160307. We would like to acknowledge the Nanomaterials Core Characterization Facility for additional characterization.

\section{Supplemental Material}

UV-vis spectra at intermediate laser irradiation times; UV-vis spectrum of control Au NPs; details of PNP catalytic reactions; additional TEM images of silica-Au NPs; XRD patterns for samples; SEM-EDS images and quantification 
of samples; characterization of silica NPs; and Cl2p XPS spectra.

\section{References}

[1] A. H. Anton Fojtik, Laser ablation of films and suspended particles in a solvent: Formation of cluster and colloid solutions, Ber. Bunsenges. Phys. Chem. 97 (2) (1993) 252-255.

[2] N. G. Semaltianos, Nanoparticles by laser ablation, Crit. Rev. Solid State Mater. Sci. 35 (2) (2010) 105-124. doi:10.1080/10408431003788233.

[3] H. Zeng, X.-W. Du, S. C. Singh, S. A. Kulinich, S. Yang, J. He, W. Cai, Nanomaterials via laser ablation/irradiation in liquid: A review, Adv. Funct. Mater. 22 (7) (2012) 1333-1353. doi:10.1002/adfm.201102295.

[4] D. Zhang, B. Gökce, S. Barcikowski, Laser synthesis and processing of colloids: Fundamentals and applications, Chem. Rev. 117 (5) (2017) 39904103. doi:10.1021/acs.chemrev.6b00468,

[5] D. Tiedemann, U. Taylor, C. Rehbock, J. Jakobi, S. Klein, W. A. Kues, S. Barcikowski, D. Rath, Reprotoxicity of gold, silver, and gold-silver alloy nanoparticles on mammalian gametes, Analyst 139 (5) (2014) 931-942. doi:10.1039/C3AN01463K.

[6] K. P. Tamarov, L. A. Osminkina, S. V. Zinovyev, K. A. Maximova, J. V. Kargina, M. B. Gongalsky, Y. Ryabchikov, A. Al-Kattan, A. P. Sviridov, M. Sentis, A. V. Ivanov, V. N. Nikiforov, A. V. Kabashin, V. Y. Timoshenko, Radio frequency radiation-induced hyperthermia using $\mathrm{Si}$ nanoparticle-based sensitizers for mild cancer therapy, Sci. Rep. 4 (2014) 7034. doi:10.1038/srep07034.

[7] T. Baati, A. Al-Kattan, M.-A. Esteve, L. Njim, Y. Ryabchikov, F. Chaspoul, M. Hammami, M. Sentis, A. V. Kabashin, D. Braguer, Ultrapure laser-synthesized silicon-based nanomaterials for biomedical applica- 
tions: in vivo assessment of safety and biodistribution, Sci. Rep. 6 (2016) 254000. doi:10.1038/srep25400.

[8] J. D. Blakemore, H. B. Gray, J. R. Winkler, A. M. Müller, $\mathrm{Co}_{3} \mathrm{O}_{4}$ nanoparticle water-oxidation catalysts made by pulsed-laser ablation in liquids, ACS Catal. 3 (11) (2013) 2497-2500. doi:10.1021/cs400639b.

[9] J. Zhang, G. C. Chen, M. Chaker, F. Rosei, D. Ma, Gold nanoparticle decorated ceria nanotubes with significantly high catalytic activity for the reduction of nitrophenol and mechanism study, Appl. Catal. B. Environ. 132 (2013) 107-115. doi:10.1016/j.apcatb.2012.11.030.

[10] S. Hu, M. Tian, E. L. Ribeiro, G. Duscher, D. Mukherjee, Tandem laser ablation synthesis in solution-galvanic replacement reaction (LASiS-GRR) for the production of PtCo nanoalloys as oxygen reduction electrocatalysts, J. Power Sources 306 (2016) 413 - 423. doi:10.1016/j.jpowsour.2015. 11.078 .

[11] J. Zhang, M. Chaker, D. Ma, Pulsed laser ablation based synthesis of colloidal metal nanoparticles for catalytic applications, J. Colloid Interface Sci. 489 (2017) 138 - 149, https://doi.org/10.1016/j.jcis.2016.07.050.

[12] E. Messina, E. Cavallaro, A. Cacciola, M. A. Iatì, P. G. Gucciardi, F. Borghese, P. Denti, R. Saija, G. Compagnini, M. Meneghetti, V. Amendola, O. M. Maragò, Plasmon-enhanced optical trapping of gold nanoaggregates with selected optical properties, ACS Nano 5 (2) (2011) 905-913. doi:10.1021/nn102101a.

[13] J. Krawinkel, U. Richter, M. L. Torres-Mapa, M. Westermann, L. Gamrad, C. Rehbock, S. Barcikowski, A. Heisterkamp, Optical and electron microscopy study of laser-based intracellular molecule delivery using peptide-conjugated photodispersible gold nanoparticle agglomerates, J. Nanobiotechnology 14 (1) (2016) 2. doi:10.1186/s12951-015-0155-8. 
[14] C.-Y. Shih, R. Streubel, J. Heberle, A. Letzel, M. V. Shugaev, C. Wu, M. Schmidt, B. Gökce, S. Barcikowski, L. V. Zhigilei, Two mechanisms of nanoparticle generation in picosecond laser ablation in liquids: the origin of the bimodal size distribution, Nanoscale 10 (2018) 6900-6910. doi: 10.1039/C7NR08614H

[15] A. Kabashin, M. Meunier, Synthesis of colloidal nanoparticles during femtosecond laser ablation of gold in water, J. Appl. Phys. 94 (2003) 7941-7943. doi:10.1063/1.1626793.

[16] A. V. Kabashin, M. Meunier, C. Kingston, J. H. T. Luong, Fabrication and characterization of gold nanoparticles by femtosecond laser ablation in an aqueous solution of cyclodextrins, J. Phys. Chem. B 107 (19) (2003) 4527-4531. doi:10.1021/jp034345q

[17] J.-P. Sylvestre, S. Poulin, A. V. Kabashin, E. Sacher, M. Meunier, J. H. T. Luong, Surface chemistry of gold nanoparticles produced by laser ablation in aqueous media, J. Phys. Chem. B 108 (43) (2004) 16864-16869. doi: $10.1021 / \mathrm{jp} 047134+$

[18] J. Xiao, Q. L. Wu, P. Liu, Y. Liang, H. B. Li, M. M. Wu, G. W. Yang, Highly stable sub-5 $\mathrm{nm} \mathrm{Sn}_{6} \mathrm{O}_{4}(\mathrm{OH})_{4}$ nanocrystals with ultrahigh activity as advanced photocatalytic materials for photodegradation of methyl orange, Nanotechnology 25 (13) (2014) 135702. doi:10.1088/0957-4484/25/13/ 135702

[19] P. Liu, Y. L. Cao, C. X. Wang, X. Y. Chen, G. W. Yang, Micro- and nanocubes of carbon with C8-like and blue luminescence, Nano Lett. 8 (8) (2008) 2570-2575. doi:10.1021/n1801392v.

[20] Z. Yan, G. Compagnini, D. B. Chrisey, Generation of AgCl cubes by excimer laser ablation of bulk $\mathrm{Ag}$ in aqueous $\mathrm{NaCl}$ solutions, J. Phys. Chem. C 115 (12) (2011) 5058-5062. doi:10.1021/jp109240s. 
[21] S. Hu, J. Sun, X. Du, F. Tian, L. Jiang, The formation of multiply twinning structure and photoluminescence of well-dispersed nanodiamonds produced by pulsed-laser irradiation, Diam. Relat. Mater. 17 (2) (2008) 142 - 146. doi:10.1016/j.diamond.2007.11.009.

[22] P. Liu, W. Cai, M. Fang, Z. Li, H. Zeng, J. Hu, X. Luo, W. Jing, Room temperature synthesized rutile $\mathrm{TiO}_{2}$ nanoparticles induced by laser ablation in liquid and their photocatalytic activity, Nanotechnology 20 (2009) 285707. doi:10.1088/0957-4484/20/28/285707.

[23] X.-W. Du, W.-J. Qin, Y.-W. Lu, X. Han, Y.-S. Fu, S.-L. Hu, Face-centeredcubic Si nanocrystals prepared by microsecond pulsed laser ablation, J. Appl. Phys. 102 (1) (2007) 013518. doi:10.1063/1.2752785.

[24] P. Liu, Y. L. Cao, X. Y. Chen, G. W. Yang, Trapping high-pressure nanophase of Ge upon laser ablation in liquid, Cryst. Growth Des. 9 (3) (2009) 1390-1393. doi:10.1021/cg800633j.

[25] M. G. John, V. K. Meader, K. M. Tibbetts, Au nanoparticle synthesis via femtosecond laser-induced photochemical reduction of $\left[\mathrm{AuCl}_{4}\right]^{-}$, in: S. Saha, S. Mondal (Eds.), Photochemistry and Photophysics, IntechOpen, 2018, Ch. 8. doi:10.5772/intechopen.75075.

[26] A. Vogel, J. Noack, G. Hüttman, G. Paltauf, Mechanisms of femtosecond laser nanosurgery of cells and tissues, Appl. Phys. B 81 (8) (2005) 10151047. doi:10.1007/s00340-005-2036-6.

[27] S. Inasawa, M. Sugiyama, Y. Yamaguchi, Bimodal size distribution of gold nanoparticles under picosecond laser pulses, J. Phys. Chem. B 109 (19) (2005) 9404-9410. doi:10.1021/jp0441240.

[28] B. Tangeysh, K. Moore Tibbetts, J. H. Odhner, B. B. Wayland, R. J. Levis, Gold nanoparticle synthesis using spatially and temporally shaped femtosecond laser pulses: Post-irradiation auto-reduction of aqueous $\left[\mathrm{AuCl}_{4}\right]^{-}$, J. Phys. Chem. C 117 (36) (2013) 18719-18727. doi:10.1021/jp4056494. 
[29] J. H. Odhner, K. Moore Tibbetts, B. Tangeysh, B. B. Wayland, R. J. Levis, Mechanism of improved Au nanoparticle size distributions using simultaneous spatial and temporal focusing for femtosecond laser irradiation of aqueous $\mathrm{KAuCl}_{4}$, J. Phys. Chem. C 118 (41) (2014) 23986-23995. doi:10.1021/jp507873n.

[30] K. Moore Tibbetts, B. Tangeysh, J. H. Odhner, R. J. Levis, Elucidating strong field photochemical reduction mechanisms of aqueous $\left[\mathrm{AuCl}_{4}\right]^{-}: \mathrm{Ki}-$ netics of multiphoton photolysis and radical-mediated reduction, J. Phys. Chem. A 120 (20) (2016) 3562-3569. doi:10.1021/acs.jpca.6b03163

[31] V. K. Meader, M. G. John, C. J. Rodrigues, K. M. Tibbetts, Roles of free electrons and $\mathrm{H}_{2} \mathrm{O}_{2}$ in the optical breakdown-induced photochemical reduction of aqueous $\left[\mathrm{AuCl}_{4}\right]^{-}$, J. Phys. Chem. A 121 (36) (2017) 67426754. doi:10.1021/acs.jpca.7b05370.

[32] T. Nakamura, Y. Mochidzuki, S. Sato, Fabrication of gold nanoparticles in intense optical field by femtosecond laser irradiation of aqueous solution, J. Mater. Res. 23 (4) (2008) 968-974. doi:10.1557/jmr.2008.0115.

[33] T. Nakamura, Y. Herbani, D. Ursescu, R. Banici, R. V. Dabu, S. Sato, Spectroscopic study of gold nanoparticle formation through high intensity laser irradiation of solution, AIP Adv. 3 (8) (2013) 082101. doi:10.1063/ 1.4817827 .

[34] H. Belmouaddine, M. Shi, P.-L. Karsenti, R. Meesat, L. Sanche, D. Houde, Dense ionization and subsequent non-homogeneous radical-mediated chemistry of femtosecond laser-induced low density plasma in aqueous solutions: Synthesis of colloidal gold, Phys. Chem. Chem. Phys. 19 (2017) 7897-7909. doi:10.1039/C6CP08080D.

[35] H. Belmouaddine, M. Shi, L. Sanche, D. Houde, Tuning the size of gold nanoparticles produced by multiple filamentation of femtosecond laser pulses in aqueous solutions, Phys. Chem. Chem. Phys. 20 (2018) 2340323413. doi:10.1039/C8CP02054J. 
[36] T. Nakamura, H. Magara, Y. Herbani, S. Sato, Fabrication of silver nanoparticles by highly intense laser irradiation of aqueous solution, Appl. Phys. A 104 (4) (2011) 1021. doi:10.1007/s00339-011-6499-5.

[37] Y. Herbani, T. Nakamura, S. Sato, Silver nanoparticle formation by femtosecond laser induced reduction of ammonia-containing $\mathrm{AgNO}_{3}$ solution, JPCS 817 (1) (2017) 012048. doi:10.1088/1742-6596/817/1/012048.

[38] V. K. Meader, M. G. John, L. M. Frias Batista, S. Ahsan, K. M. Tibbetts, Radical chemistry in a femtosecond laser plasma: Photochemical reduction of $\mathrm{Ag}^{+}$in liquid ammonia solution, Molecules 23 (3) (2018) 532. doi: $10.3390 / \mathrm{molecules} 23030532$

[39] J. L. H. Chau, C.-Y. Chen, M.-C. Yang, K.-L. Lin, S. Sato, T. Nakamura, C.-C. Yang, C.-W. Cheng, Femtosecond laser synthesis of bimetallic PtAu nanoparticles, Mater. Lett. 65 (4) (2011) 804 - 807. doi:10.1016/j. matlet.2010.10.088

[40] M. S. I. Sarker, T. Nakamura, Y. Herbani, S. Sato, Fabrication of Rh based solid-solution bimetallic alloy nanoparticles with fully-tunable composition through femtosecond laser irradiation in aqueous solution, Appl. Phys. A 110 (1) (2012) 145-152. doi:10.1007/s00339-012-7467-4.

[41] Y. Herbani, T. Nakamura, S. Sato, Synthesis of platinum-based binary and ternary alloy nanoparticles in an intense laser field, J. Colloid Interface Sci. 375 (1) (2012) 78 - 87. doi:10.1016/j.jcis.2012.02.030

[42] Y. Herbani, T. Nakamura, S. Sato, Spectroscopic monitoring on irradiationinduced formation of AuAg alloy nanoparticles by femtosecond laser, AIP Conf. Proc. 1711 (1) (2016) 030005. doi:10.1063/1.4941620.

[43] C. J. Rodrigues, J. A. Bobb, M. G. John, S. P. Fisenko, M. S. El-Shall, K. M. Tibbetts, Nucleation and growth of gold nanoparticles initiated by nanosecond and femtosecond laser irradiation of aqueous $\left[\mathrm{AuCl}_{4}\right]^{-}$, 
Phys. Chem. Chem. Phys. 20 (45) (2018) 28465-28475. doi:10.1039/ C8CP05774E,

[44] S. I. Kudryashov, V. D. Zvorykin, Microscale nanosecond laser-induced optical breakdown in water, Phys. Rev. E 78 (2008) 036404. doi:10.1103/ PhysRevE.78.036404

[45] E. Jiménez, K. Abderrafi, J. Martínez-Pastor, R. Abargues, J. L. Valdés, R. Ibáñez, A novel method of nanocrystal fabrication based on laser ablation in liquid environment, Superlattices Microstruct. 43 (5) (2008) 487 493, proceedings of the 7th International Conference on Physics of LightMatter Coupling in Nanostructures. doi:10.1016/j.spmi.2007.06.025.

[46] E. Jiménez, K. Abderrafi, R. Abargues, J. L. Valdés, J. P. Martínez-Pastor, Laser-ablation-induced synthesis of $\mathrm{SiO}_{2}$-capped noble metal nanoparticles in a single step, Langmuir 26 (10) (2010) 7458-7463. doi:10.1021/ 1 a904179x.

[47] P. Liu, H. Chen, H. Wang, J. Yan, Z. Lin, G. Yang, Fabrication of Si/Au core/shell nanoplasmonic structures with ultrasensitive surface-enhanced raman scattering for monolayer molecule detection, J. Phys. Chem. C 119 (2) (2015) 1234-1246. doi:10.1021/jp5111482.

[48] V. A. Ermakov, E. Jimenez-Villar, J. M. C. d. Silva Filho, E. Yassitepe, N. V. V. Mogili, F. Iikawa, G. F. de Sá, C. L. Cesar, F. C. Marques, Size control of silver-core/silica-shell nanoparticles fabricated by laser-ablationassisted chemical reduction, Langmuir 33 (9) (2017) 2257-2262. doi:10. 1021/acs. langmuir.6b04308

[49] I. N. Saraeva, N. V. Luong, S. I. Kudryashov, A. A. Rudenko, R. A. Khmelnitskiy, A. L. Shakhmin, A. Y. Kharin, A. A. Ionin, D. A. Zayarny, D. H. Tung, P. V. Duong, P. H. Minh, Laser synthesis of colloidal $\mathrm{Si} @ \mathrm{Au}$ and $\mathrm{Si@Ag}$ nanoparticles in water via plasma-assisted reduction, J. Photochem. Photobiol. A: Chem. 360 (2018) 125 - 131. doi: $10.1016 / j$.jphotochem. 2018.04.004. 
[50] S. Hu, C. Melton, D. Mukherjee, A facile route for the synthesis of nanostructured oxides and hydroxides of cobalt using laser ablation synthesis in solution (LASIS), Phys. Chem. Chem. Phys. 16 (2014) 24034. doi:10.1039/C4CP03018D.

[51] S. Hu, K. Cheng, E. L. Ribeiro, K. Park, B. Khomami, D. Mukherjee, A facile and surfactant-free route for nanomanufacturing of tailored ternary nanoalloys as superior oxygen reduction reaction electrocatalysts, Catal. Sci. Technol. 7 (2017) 2074-2086. doi:10.1039/C7CY00073A.

[52] S. Hu, G. Goenaga, C. Melton, T. A. Zawodzinski, D. Mukherjee, PtCo/CoOx nanocomposites: Bifunctional electrocatalysts for oxygen reduction and evolution reactions synthesized via tandem laser ablation synthesis in solution-galvanic replacement reactions, Appl. Catal. B: Environ. 182 (2016) 286 - 296. doi:10.1016/j.apcatb.2015.09.035.

[53] M. Haruta, N. Yamada, T. Kobayashi, S. Iijima, Gold catalysts prepared by coprecipitation for low-temperature oxidation of hydrogen and of carbon monoxide, J. Catal. 115 (2) (1989) 301 - 309. doi:10.1016/ 0021-9517(89)90034-1.

[54] Y. Tai, W. Yamaguchi, K. Tajiri, H. Kageyama, Structures and CO oxidation activities of size-selected Au nanoparticles in mesoporous titaniacoated silica aerogels, Appl. Catal. A 364 (1-2) (2009) 143 - 149. doi: $10.1016 /$ j. apcata.2009.05.041.

[55] K. Qian, L. Luo, H. Bao, Q. Hua, Z. Jiang, W. Huang, Catalytically active structures of $\mathrm{SiO}_{2}$-supported $\mathrm{Au}$ nanoparticles in low-temperature $\mathrm{CO}$ oxidation, Catal. Sci. Technol. 3 (2013) 679-687. doi:10.1039/C2CY20481A.

[56] L. Di, W. Xu, Z. Zhan, X. Zhang, Synthesis of alumina supported Pd-Cu alloy nanoparticles for $\mathrm{CO}$ oxidation via a fast and facile method, RSC Adv. 5 (88) (2015) 71854-71858. doi:10.1039/C5RA13813B. 
[57] J. Lam, J. Lombard, C. Dujardin, G. Ledoux, S. Merabia, D. Amans, Dynamical study of bubble expansion following laser ablation in liquids, Appl. Phys. Lett. 108 (7) (2016) 074104. doi:10.1063/1.4942389.

[58] A. Matsumoto, A. Tamura, T. Honda, T. Hirota, K. Kobayashi, S. Katakura, N. Nishi, K.-i. Amano, K. Fukami, T. Sakka, Transfer of the species dissolved in a liquid into laser ablation plasma: An approach using emission spectroscopy, J. Phys. Chem. C 119 (47) (2015) 26506-26511. doi:10.1021/acs.jpcc.5b07769.

[59] P. Wagener, S. Ibrahimkutty, A. Menzel, A. Plech, S. Barcikowski, Dynamics of silver nanoparticle formation and agglomeration inside the cavitation bubble after pulsed laser ablation in liquid, Phys. Chem. Chem. Phys. 15 (9) (2013) 3068-3074. doi:10.1039/C2CP42592K.

[60] J. Lee, J. C. Park, H. Song, A nanoreactor framework of a $\mathrm{Au} @ \mathrm{SiO}_{2}$ yolk/shell structure for catalytic reduction of p-nitrophenol, Adv. Mater. 20 (8) (2008) 1523-1528. doi:10.1002/adma.200702338.

[61] P. Zhao, X. Feng, D. Huang, G. Yang, D. Astruc, Basic concepts and recent advances in nitrophenol reduction by gold- and other transition metal nanoparticles, Coord. Chem. Rev. 287 (2015) 114 - 136. doi: $10.1016 / \mathrm{j} . \mathrm{ccr} .2015 .01 .002$

[62] B. Puértolas, Á. Mayoral, R. Arenal, B. Solsona, A. Moragues, S. MurciaMascaros, P. Amorós, A. B. Hungría, S. H. Taylor, T. García, Hightemperature stable gold nanoparticle catalysts for application under severe conditions: The role of $\mathrm{TiO}_{2}$ nanodomains in structure and activity, ACS Catal. 5 (2) (2015) 1078-1086. doi:10.1021/cs501741u.

[63] D. Gajan, C. Copéret, Silica-supported single-site catalysts: to be or not to be? a conjecture on silica surfaces, New J. Chem. 35 (2011) 2403. doi: $10.1039 / \mathrm{C} 1 \mathrm{NJ} 20506 \mathrm{D}$ 
[64] P. Heimann, J. van der Veen, D. Eastman, Structure-dependent surface core level shifts for the $\mathrm{Au}(111),(100)$, and (110) surfaces, Sol. Stat. Commun. 38 (1981) 595-598. doi:10.1016/0038-1098(81)90947-9.

[65] A. Y. Klyushin, T. C. R. Rocha, M. Hävecker, A. Knop-Gericke, R. Schlögl, A near ambient pressure XPS study of Au oxidation, Phys. Chem. Chem. Phys. 16 (2014) 7881-7886. doi:10.1039/C4CP00308J.

[66] C. Weststrate, E. Lundgren, J. Andersen, E. Rienks, A. Gluhoi, J. Bakker, I. Groot, B. Nieuwenhuys, Co adsorption on $\mathrm{Au}(310)$ and $\mathrm{Au}(321)$ : 6fold coordinated gold atoms, Surf. Sci. 603 (13) (2009) 2152 - 2157. doi: $10.1016 /$ j.susc. 2009.04 .026

[67] B. Koslowski, H.-G. Boyen, C. Wilderotter, G. Kästle, P. Ziemann, R. Wahrenberg, P. Oelhafen, Oxidation of preferentially (111)-oriented $\mathrm{Au}$ films in an oxygen plasma investigated by scanning tunneling microscopy and photoelectron spectroscopy, Surf. Sci. 475 (1) (2001) $1-10$. doi:10.1016/S0039-6028(00)00986-9.

[68] T. Gross, M. Ramm, H. Sonntag, W. Unger, H. M. Weijers, E. H. Adem, An XPS analysis of different $\mathrm{SiO}_{2}$ modifications employing a $\mathrm{C} 1 \mathrm{~s}$ as well as an Au4f 7/2 static charge reference, Surf. Interf. Anal. 18 (1992) 59-64.

[69] K. J. Kim, K. T. Park, J. W. Lee, Thickness measurement of $\mathrm{SiO}_{2}$ films thinner than $1 \mathrm{~nm}$ by X-ray photoelectron spectroscopy, Thin Solid Films 500 (1) (2006) 356 - 359. doi:10.1016/j.tsf.2005.11.042.

[70] O. Sublemontier, C. Nicolas, D. Aureau, M. Patanen, H. Kintz, X. Liu, M.-A. Gaveau, J.-L. Le Garrec, E. Robert, F.-A. Barreda, A. Etcheberry, C. Reynaud, J. B. Mitchell, C. Miron, X-ray photoelectron spectroscopy of isolated nanoparticles, J. Phys. Chem. Lett. 5 (19) (2014) 3399-3403. doi:10.1021/jz501532c.

[71] F. J. Himpsel, F. R. McFeely, A. Taleb-Ibrahimi, J. A. Yarmoff, 
G. Hollinger, Microscopic structure of the $\mathrm{SiO}_{2} / \mathrm{Si}$ interface, Phys. Rev. B 38 (1988) 6084-6096. doi:10.1103/PhysRevB.38.6084.

[72] C.-Y. Shih, C. Wu, M. V. Shugaev, L. V. Zhigilei, Atomistic modeling of nanoparticle generation in short pulse laser ablation of thin metal films in water, J. Colloid Interface Sci. 489 (2017) 3 - 17. doi:10.1016/j.jcis. 2016.10.029.

[73] F. J. Grunthaner, P. J. Grunthaner, R. P. Vasquez, B. F. Lewis, J. Maserjian, Local atomic and electronic structure of oxide/GaAs and $\mathrm{SiO}_{2} / \mathrm{Si}$ interfaces using high-resolution XPS, J. Vac. Sci. Techn 16 (1979) 1443. doi:10.1116/1.570218.

[74] M. T. K. Soh, J. H. Thomas, J. J. Talghader, Thermally induced structural changes in nanoporous silicon dioxide from X-ray photoelectron spectroscopy, J. Vac. Sci. Techn. A 24 (6) (2006) 2147-2150. doi:10.1116/1. 2359734

[75] E. Görlich, J. Haber, A. Stoch, J. Stoch, XPS study of a-quartz surface, J. Sol. St. Chem 33 (1980) 121-124. doi:10.1016/0022-4596(80)90555-1.

[76] J. Radnik, C. Mohr, P. Claus, On the origin of binding energy shifts of core levels of supported gold nanoparticles and dependence of pretreatment and material synthesis, Phys. Chem. Chem. Phys. 5 (2003) 172-177. doi: 10.1039/B207290D.

[77] A. K. Bhattacharya, D. R. Pyke, R. Reynolds, G. S. Walker, W. C. R., The use of O1s charge referencing for the X-ray photoelectron spectroscopy of $\mathrm{Al} / \mathrm{Si}, \mathrm{Al} / \mathrm{Ti}$ and $\mathrm{Al} / \mathrm{Zr}$ mixed oxides, J. Mater. Sci. Let. 16 (1997) 1-3. doi:10.1023/A:1018521126248.

[78] J. F. Moulder, W. F. Stickle, P. E. Sobol, K. D. Bomben, Handbook of Xray Photoelectron Spectroscopy, Perkin-Elmer Corp., Physical Electronics Division, 1979. 
[79] B. Crist, The Handbooks of Monochromatic XPS Spectra Series: Commercially Pure Binary Oxides, Vol. 2, XPS International, 2004.

[80] S. M. Francis, W. E. Stephens, N. V. Richardson, X-ray photoelectron and infrared spectroscopies of quartz samples of contrasting toxicity, Environ. Health 8 (1) (2009) S4. doi:10.1186/1476-069X-8-S1-S4.

[81] S. Geng, S. Zhang, H. Onishi, XPS applications in thin films research, Mater. Tech. 17 (4) (2002) 234-240. doi:10.1080/10667857.2002. 11752992.

[82] N. Pradhan, A. Pal, T. Pal, Silver nanoparticle catalyzed reduction of aromatic nitro compounds, Colloids Surf. A: Physicochem. Eng. Asp. 196 (2) (2002) 247 - 257. doi:10.1016/S0927-7757(01)01040-8.

[83] S. Wunder, F. Polzer, Y. Lu, Y. Mei, M. Ballauff, Kinetic analysis of catalytic reduction of 4-nitrophenol by metallic nanoparticles immobilized in spherical polyelectrolyte brushes, J. Phys. Chem. C 114 (19) (2010) 88148820. doi:10.1021/jp101125j.

[84] K. Kuroda, T. Ishida, M. Haruta, Reduction of 4-nitrophenol to 4aminophenol over Au nanoparticles deposited on PMMA, J. Mol. Catal. A: Chem. 298 (1) (2009) 7 -11. doi:10.1016/j.molcata.2008.09.009.

[85] P. Hervés, M. Pérez-Lorenzo, L. M. Liz-Marzán, J. Dzubiella, Y. Lu, M. Ballauff, Catalysis by metallic nanoparticles in aqueous solution: model reactions, Chem. Soc. Rev. 41 (2012) 5577. doi:10.1039/C2CS35029G.

[86] D. von der Linde, K. Sokolowski-Tinten, J. Bialkowski, Laser-solid interaction in the femtosecond time regime, Appl. Surf. Sci. 109-110 (1997) 1 10. doi:10.1016/S0169-4332(96)00611-3.

[87] E. Gamaly, Femtosecond Laser-Matter Interactions: Theory, Experiments and Applications, 1st Edition, Pan Stanford, 2011. 
[88] E. G. Gamaly, A. V. Rode, B. Luther-Davies, V. T. Tikhonchuk, Ablation of solids by femtosecond lasers: Ablation mechanism and ablation thresholds for metals and dielectrics, Phys. Plasmas 9 (3) (2002) 949-957. doi:10.1063/1.1447555.

[89] A. A. Ionin, S. I. Kudryashov, L. V. Seleznev, D. V. Sinitsyn, A. F. Bunkin, V. N. Lednev, S. M. Pershin, Thermal melting and ablation of silicon by femtosecond laser radiation, J. Exp. Theor. Phys. 116 (3) (2013) 347-362. doi:10.1134/S106377611302012X.

[90] S. Pommeret, F. Gobert, M. Mostafavi, I. Lampre, J.-C. Mialocq, Femtochemistry of the hydrated electron at decimolar concentration, J. Phys. Chem. A 105 (51) (2001) 11400-11406. doi:10.1021/jp0123381.

[91] A. Reuther, A. Laubereau, D. N. Nikogosyan, Primary photochemical processes in water, J. Phys. Chem. 100 (42) (1996) 16794-16800. doi: $10.1021 / \mathrm{jp} 961462 \mathrm{v}$

[92] D. Behar, J. Rabani, Kinetics of hydrogen production upon reduction of aqueous $\mathrm{TiO}_{2}$ nanoparticles catalyzed by $\mathrm{Pd}^{0}, \mathrm{Pt}^{0}$, or $\mathrm{Au}^{0}$ coatings and an unusual hydrogen abstraction; steady state and pulse radiolysis study, J. Phys. Chem. B 110 (17) (2006) 8750-8755. doi:10.1021/jp060971m.

[93] D. N. Nikogosyan, A. A. Oraevsky, V. I. Rupasov, Two-photon ionization and dissociation of liquid water by powerful laser UV radiation, Chem. Phys. 77 (1) (1983) 131 - 143. doi:10.1016/0301-0104(83)85070-8

[94] C. Wang, H. Huo, M. Johnson, M. Shen, E. Mazur, The thresholds of surface nano-/micro-morphology modifications with femtosecond laser pulse irradiations, Nanotechnology 21 (7) (2010) 075304. doi:10.1088/ $0957-4484 / 21 / 7 / 075304$

[95] P. Lorazo, L. J. Lewis, M. Meunier, Thermodynamic pathways to melting, ablation, and solidification in absorbing solids under pulsed laser irradiation, Phys. Rev. B 73 (2006) 134108. doi:10.1103/PhysRevB.73.134108 